\title{
Влияние никеля на время жизни носителей заряда в кремниевых солнечных элементах
}

\author{
(C) М.К. Бахадырханов ${ }^{1}$, 3.Т. Кенжаев ${ }^{2, \uparrow, ~ С . В . ~ К о в е ш н и к о в ~}{ }^{1}$, К.С. Аюпов ${ }^{1}$, Е.Ж. Косбергенов ${ }^{2}$ \\ ${ }^{1}$ Ташкентский государственный технический университет, \\ 100095 Ташкент, Узбекистан \\ ${ }^{2}$ Каракалпакский государственный университет, \\ 230112 Нукус, Узбекистан \\ I E-mail: zoir1991@bk.ru
}

Поступила в Редакцию 1 марта 2021 г.

В окончательной редакции 20 июня 2021 r.

Принята к публикации 18 августа 2021 г.

\begin{abstract}
Экспериментально показано, что кластеры никеля на поверхности кремниевого образца содержат большое количество кислорода и рекомбинационных примесей - $\mathrm{Cu}, \mathrm{Fe}, \mathrm{Cr}$, что указывает на эффективное геттерирование примесей кластерами. Определена оптимальная температура диффузии никеля в кремний: $800-850^{\circ} \mathrm{C}$. Легирование примесными атомами никеля с образованием кластеров позволяет увеличить время жизни неравновесных носителей заряда в базе солнечного элемента до 2 раз, при этом формирование обогащенной никелем области в лицевом слое оказалось более эффективным. Показано, что эффект влияния дополнительного легирования никелем слабо зависит от последовательности проведения процессов диффузии никеля и создания рабочего $p-n$-перехода.
\end{abstract}

Ключевые слова: кремниевые солнечные элементы, диффузия никеля, неравновесные носители заряда, геттерирование, $p-n$-переход.

DOI: 10.21883/FTP.2022.01.51823.9642

\section{1. Введение}

Качество монокристаллов кремния для солнечных элементов определяется величиной времени жизни носителей заряда $(\tau)$. В процессе изготовления солнечных элементов (главным образом при применении высокотемпературных обработок выше $\left.1000^{\circ} \mathrm{C}\right) \tau$ может уменьшиться из-за активизации неконтролируемых (фоновых) примесных атомов переходных металлов (Fe, $\mathrm{Cu}$ и др.) [1,2].

Поэтому увеличение времени жизни неравновесных носителей заряда (ННЗ) является главным критерием оптимизации технологии солнечных элементов (СЭ). С ростом времени жизни увеличивается ток короткого замыкания $\left(I_{s c}\right)$ и напряжение холостого хода $\left(V_{o c}\right)$ вследствие уменьшения обратного тока насыщения $[3,4]$.

Основной способ увеличения времени жизни в структурах СЭ - геттерирование. Геттерирование примесных атомов позволяет не только повысить время жизни ННЗ, но также обеспечивает стабильность электрических и рекомбинационных параметров материала, который многократно подвергается термообработке в процессе изготовления СЭ [5].

Геттерирование в основном осуществляется введением различных примесных атомов [6,7] в объем лазерной обработкой [8], а также созданием на поверхности кремния пористого или аморфного слоя при помощи ионной имплантации [9].

Известно [10,11], что никель в кремнии имеет достаточно высокую объемную растворимость (до концентраций $N \sim 10^{18} \mathrm{~cm}^{-3}$ ), а в приповерхностной обла- сти $(d=2-3$ мкм) его концентрация может достигать $N_{S} \sim\left(10^{20}-10^{21}\right) \mathrm{cm}^{-3}$. Основная часть растворенных в объеме атомов, 99.999\%, а в приповерхностной области еще больше, находится в электронейтральном состоянии в междоузлиях и при определенных условиях термообработки может формировать кластеры $[12,13]$. Кластеры никеля легко образуются как в процессе диффузии, так и при дальнейшей термообработке, но они практически не влияют на электрические параметры самого материала при термообработках в диапазоне температур $T=400-1000^{\circ} \mathrm{C}[14]$.

Размеры, концентрация, структура и состав кластеров в основном определяются температурой дополнительного отжига и общей концентрацией введенных в кремний атомов никеля [15]. Кроме того, известно, что пленки никеля, нанесенные на кремний, проявляют эффект геттерирования [16].

В данной статье анализируются эффективность геттерирования неконтролируемых примесных атомов кластерами атомов никеля и их влияние на параметры СЭ. Эффективность геттерирования определяет время жизни НН3 в базе СЭ.

В связи с этим были поставлены следующие задачи: показать наличие геттерирующих свойств кластеров никеля; экспериментально показать влияние никеля на время жизни ННЗ в базе СЭ; установить закономерности изменения $\tau$ в базе СЭ в зависимости от температуры диффузии никеля; оценить возможность легирования кремния никелем до создания $p-n$-перехода; исследовать влияние параметров обогащенного никелем слоя на время жизни НН3. 


\section{2. Технология и метод исследования}

Для изучения влияния никеля на время жизни НН3 нами были изготовлены СЭ, в которых $p-n$ переход создавался диффузией фосфора в кремниевые пластины $p$-типа проводимости, выращенные методом Чохральского с удельным сопротивлением $0.5 \mathrm{OM} \cdot \mathrm{cm}$ (КДБ-0.5), толщиной 380 мкм и диаметром $d \approx 76$ мм при $T_{\text {diff }}=1000^{\circ} \mathrm{C}$ в течение времени $t=0.5$ ч.

После получения $p-n$-перехода пластины разрезалась на отдельные образцы размером $1 \times 1 \mathrm{~cm}$. Часть образцов оставили для контроля. На остальные образцы напыляли в вакууме тонкий слой чистого никеля толщиной 1 мкм и проводили диффузию при разных температурах (в соответствии с целями эксперимента). После диффузии никеля все образцы проходили дополнительный термический отжиг при $T_{\mathrm{ann}}=750-800^{\circ} \mathrm{C}$ в течение $t=30$ мин с целью активации процесса геттерирования $[17,18]$ неконтролируемых рекомбинационных примесей. После диффузии никеля и термического отжига образцы охлаждались на воздухе.

После каждого технологического этапа проводились очистка поверхности и химическая обработка, чтобы снять остатки никеля и оксид кремния с поверхности $(10 \% \mathrm{HCl}, 10 \% \mathrm{HF})$.

Напылением никеля создавались омические контакты. На тыльной стороне напылялся сплошной контакт, а на лицевой - через трафарет с шириной полосок 0.5 мм и шагом 2 мм. Просветляющее покрытие на поверхности элементов отсутствовало.

Время жизни ННЗ измерялось в полученных структуpax методом [19]. Время жизни в структурах СЭ соответствует времени восстановления обратной проводимости $p-n$-перехода, которое измерялось с использованием затухающих колебаний резонансного $L C$-контура, ошибка измерений не превышала $10 \%$.

\section{3. Экспериментальные результаты}

\section{1. Геттерирующие свойства кластеров атомов никеля}

Нами на основе технологии, описанной в [14,15], были изготовлены образцы монокристаллического кремния, легированного никелем (без $p-n$-перехода). На сканирующем электронном микроскопе TESCAN MIRA 3 исследовался элементный состав кластеров никеля на поверхности кремниевого образца.

Установлено, что из атомов никеля формируются кластеры, на рисунке представлен состав кластеров атомов никеля. Кластеры на поверхности кремниевого образца состоят в основном из атомов кремния $(84.93$ ат\%) и никеля (13.38 ат\%), в них также имеются $\mathrm{Cu}, \mathrm{Fe}, \mathrm{Cr}$.

Таким образом, можно предположить, что кластеры атомов никеля геттерируют быстро диффундирующие примеси, которые действуют как рекомбинационные центры.

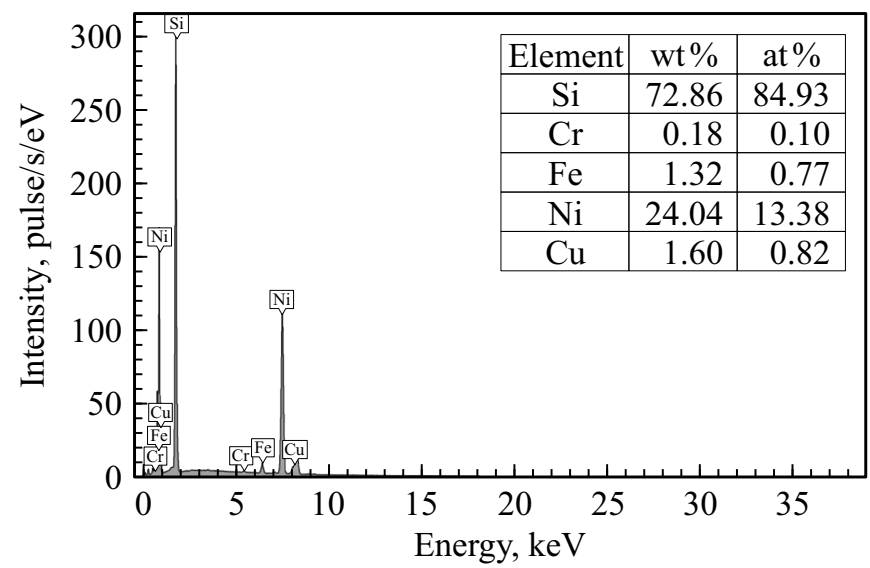

Состав кластеров примесных атомов, полученный с помощью зондового элементного анализа на сканирующем электронном микроскопе TESCAN MIRA 3.

Также исследовалось влияние никеля на количество кислорода в кремнии. Нами на основе технологии, описанной в работе [18], были изготовлены образцы солнечных элементов, легированных никелем после формирования $p-n$-перехода на лицевой стороне. Концентрацию кислорода определяли методом инфракрасной спектрометрии, как после диффузии никеля (при $T_{\text {diff }}=1200^{\circ} \mathrm{C}$ ), так и после дополнительного термического отжига (при $T_{\mathrm{ann}}=800^{\circ} \mathrm{C}$ ).

Как видно из табл. 1, концентрация кислорода в образцах с никелем в 2 раза ниже, чем в контрольных. После дополнительного термического отжига концентрация кислорода в образцах, легированных никелем, уменьшается в 4.44 раза.

Это означает, что введение никеля является не только достаточно эффективным методом геттерирования различных вредных примесей, но и уменьшает концентрацию кислорода в объеме кремния, т.е. геттерирует кислород.

Кластеры атомов никеля содержат значительное количество кремния и кислорода, а также действуют эффективными стоками (центрами геттерирования) различных вредных неконтролируемых примесных атомов. Это может привести к существенному снижению концентрации различных рекомбинационных центров и увеличению времени жизни НHЗ, в первую очередь за счет формирования нано- и микрокластеров атомов никеля в приповерхностных слоях, имеющих высокую концентрацию

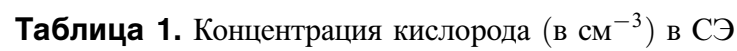

\begin{tabular}{c|c|c}
\hline \multicolumn{1}{c|}{ Тип СЭ } & Контрольные & $\begin{array}{c}\text { Легированные } \\
\text { никелем }\end{array}$ \\
\hline $\begin{array}{l}\text { После диффузии никеля } \\
\text { После дополнительного } \\
\text { термического отжига }\end{array}$ & $6.8 \cdot 10^{18}$ & $3.2 \cdot 10^{18}$ \\
\hline
\end{tabular}


Таблица 2. Времена жизни ННЗ

\begin{tabular}{c|c|c|c}
\hline Группа & I & II & III \\
\hline$\tau$, мкс & $5-7$ & $7-9$ & $10-12$
\end{tabular}

никеля. Это подтверждается работами [13,14], где атомы никеля геттерируют атомы растворенного в кремнии кислорода с образованием кластеров, содержащих кроме никеля значительные концентрации кислорода, кремния и различных рекомбинационных примесей.

\section{2. Влияние никеля на время жизни неравновесных носителей заряда в базе солнечного элемента}

После формирования $p-n$-перехода создавались три разных группы СЭ: группа I - контрольная, в группе II после диффузии фосфора напылялся никель на тыльную сторону, в группе III - на лицевую сторону. Диффузия никеля проводилась при $T_{\text {diff }}=1200^{\circ} \mathrm{C}$ в течение $t=30$ мин, а затем выполнялся дополнительный термический отжиг при $T_{\text {ann }}=800^{\circ} \mathrm{C}$ в течение $t=1$ ч. При этом во всех группах образцов за счет разгонки фосфора глубина $p-n$-перехода увеличилась до $x_{p-n}=4.5-5$ мкм.

После этого измерялось время жизни ННЗ в полученных структурах (табл. 2).

Видно, что время жизни ННЗ контрольного СЭ составляет $\tau=5-7$ мкс, это соответствует типичным значениям времени жизни для таких структур [20-22]. В группах II и III $\tau$ увеличивается в 1.5 и 2 раза. Это позволяет утверждать, что: легирование примесными атомами никеля приводит к увеличению времени жизни ННЗ $\tau$ в базе СЭ; формирование обогащенной никелем области в лицевом слое дополнительно увеличивает $\tau$ СЭ.

В этом исследовании легирование кремния никелем проводилось при достаточно высокой температуре $\left(T_{\text {diff }}=1200^{\circ} \mathrm{C}\right)$ и после формирования $p-n$-перехода, что может уменьшать эффективность солнечного элемента из-за разгонки фосфора.

\section{3. Изменения $\tau$ в базе солнечного элемента в зависимости от температуры диффузии никеля}

Дальнейшей задачей был выбор оптимальной температуры диффузии никеля для увеличения времени жизни ННЗ.

В табл. 3 показаны времена жизни НН3 в базе СЭ, легированных никелем после создания $p-n$-перехода при температурах $T_{\text {diff }}$ в диапазоне $750-1250^{\circ} \mathrm{C}$. Полученные результаты экспериментов показывают, что с уменышением температуры диффузии никеля время жизни ННЗ увеличивается и достигает максимального значения при $T_{\text {diff }}=800-850^{\circ} \mathrm{C}$.

Диффузия никеля, проведенная при более низких температурах, $T_{\text {diff }}=750-700^{\circ} \mathrm{C}$, приводила к незначительному ухудшению параметров солнечных элементов по отношению к образцам, полученным при $T_{\text {diff }}=800^{\circ} \mathrm{C}$.

\section{4. Возможности формирования обогащенного никелем слоя до создания $p-n$-перехода солнечного элемента}

Вышеприведенные результаты получены в случае, когда обогащенная никелем область в СЭ создавалась после формирования $p-n$-перехода. Однако с точки зрения технологии это неудобно. Поэтому представляет интерес возможность формирования обогащенного никелем слоя до создания $p-n$-перехода.

Для этого исследования были изготовлены СЭ из монокристаллических кремниевых пластин с удельным сопротивлением 0.5 Ом · см. Создавались три группы образцов: группа I - контрольная; группа IIIa - образцы, в которых диффузия примесных атомов никеля проводилась после создания $p-n$-перехода; группа IIIb образцы, в которых диффузия примесных атомов никеля проводилась до создания $p-n$-перехода.

Условия проведения диффузии фосфора и никеля в образцах групп IIIa и IIIb были одинаковыми. Диффузия фосфора проводилась при $T_{\text {diff }}=1000^{\circ} \mathrm{C}$ в течение $t=30$ мин, диффузия никеля проводилась при $T_{\text {diff }}=800^{\circ} \mathrm{C}$ в течение $t=30$ мин. Для всех структур СЭ проводился дополнительный термический отжиг при $T_{\text {ann }}=750^{\circ} \mathrm{C}$ в течение $t=30$ мин. Далее были измерены основные параметры СЭ и время жизни ННЗ (табл. 4).

Видно, что технология легирования никелем до формирования $p-n$-перехода дополнительно улучшает параметры солнечных элементов. Введение этапа легирования никелем до формирования $p-n$-перехода практически не усложняет технологию изготовления СЭ, но повышает эффективность.

Таким образом, на основе полученных результатов можно утверждать, что эффект влияния дополнительного легирования никелем слабо зависит от метода его введения, а наличие обогащенного никелем слоя на лицевой стороне кремниевого солнечного элемента (группа III) приводит к улучшению параметров.

\section{5. Влияние обогащенного никелем слоя на время жизни неравновесных носителей заряда в базе солнечного элемента}

Известно, что распределение атомов никеля при диффузии имеет существенную неоднородность - высокая, быстро спадающая концентрация вблизи поверхности и сравнительно постоянная в объеме [23]. После дополнительного отжига характер распределения мало меняется, однако возникают кластеры, геттерирующие примеси. 
Таблица 3. При диффузии $T_{\text {diff }}=1100^{\circ} \mathrm{C}$ значение времени жизни ННЗ в СЭ, легированном никелем, равно $14-16$ мкс

\begin{tabular}{|c|c|c|c|c|c|c|}
\hline$T_{\text {diff, }}{ }^{\circ} \mathrm{C}$ & $t_{\text {diff, МИн }}$ & $T_{\mathrm{ann}},{ }^{\circ} \mathrm{C}$ & $t_{\mathrm{ann}}$, Мин & $x_{p-n}$, МКМ & Группа & $\tau$, мкс \\
\hline 1250 & 3 & 800 & 30 & $2.0-2.5$ & $\begin{array}{c}\text { III } \\
\text { I }\end{array}$ & $\begin{array}{c}10-12 \\
5-7\end{array}$ \\
\hline 1200 & 3 & 800 & 30 & $1.5-2$ & $\begin{array}{c}\text { III } \\
\text { I }\end{array}$ & $\begin{array}{c}10-14 \\
5-7\end{array}$ \\
\hline 1150 & 5 & 800 & 30 & $1-1.5$ & $\begin{array}{c}\text { III } \\
\text { I }\end{array}$ & $\begin{array}{c}10-14 \\
5-7\end{array}$ \\
\hline 1100 & 5 & 800 & 30 & $0.9-1.2$ & $\begin{array}{c}\text { III } \\
\text { I }\end{array}$ & $\begin{array}{r}414-16 \\
8-10\end{array}$ \\
\hline 1050 & 7 & 800 & 30 & $0.8-0.9$ & $\begin{array}{c}\text { III } \\
\text { I }\end{array}$ & $\begin{array}{l}16-18 \\
10-12\end{array}$ \\
\hline 1000 & 10 & 800 & 30 & $0.7-0.8$ & $\begin{array}{c}\text { III } \\
\text { I }\end{array}$ & $\begin{array}{l}18-20 \\
10-14\end{array}$ \\
\hline 950 & 15 & 800 & 30 & $0.6-0.7$ & $\begin{array}{c}\text { III } \\
\text { I }\end{array}$ & $\begin{array}{l}22-26 \\
12-14\end{array}$ \\
\hline 900 & 20 & 800 & 30 & $0.6-0.7$ & $\begin{array}{c}\text { III } \\
\text { I }\end{array}$ & $\begin{array}{l}26-30 \\
12-15\end{array}$ \\
\hline 850 & 30 & 750 & 30 & $0.5-0.7$ & $\begin{array}{c}\text { III } \\
\text { I }\end{array}$ & $\begin{array}{l}30-32 \\
14-16\end{array}$ \\
\hline 800 & 30 & 750 & 30 & $0.5-0.7$ & $\begin{array}{c}\text { III } \\
\text { I }\end{array}$ & $\begin{array}{l}30-32 \\
14-16\end{array}$ \\
\hline 750 & 45 & 750 & 30 & $0.5-0.7$ & $\begin{array}{c}\text { III } \\
\text { I }\end{array}$ & $\begin{array}{l}22-26 \\
14-16\end{array}$ \\
\hline
\end{tabular}

Примечание. $T_{\mathrm{diff}}$ - температура диффузии никеля, $t_{\mathrm{diff}}-$ время диффузии, $T_{\mathrm{ann}}-$ температура дополнительного термоотжига, $t_{\mathrm{ann}}-$ время отжига, $x_{p-n}-$ расчетная глубина $p-n$-перехода.

Таблица 4. Средние значения параметров СЭ, полученных при температурах диффузии никеля $T_{\text {diff }}=800^{\circ} \mathrm{C}$

\begin{tabular}{c|c|c|c}
\hline Группа & I (контрольная) & $\begin{array}{c}\text { IIIa } \\
\text { (диффузия никеля после } \\
\text { создания } p-n \text {-перехода) }\end{array}$ & $\begin{array}{c}\text { (диффузия никеля } \\
\text { до создания } p-n \text {-перехода) }\end{array}$ \\
\hline$J_{s c}, \mathrm{MA} / \mathrm{cm}^{2}$ & 32 & 37.5 & 38.5 \\
$V_{o c}, \mathrm{MB}$ & 590 & 600 & 605 \\
$\xi$ & 0.640 & 0.68 & 0.67 \\
$P_{\max }, \mathrm{MB} / \mathrm{cm}^{2}$ & 12.08 & 15.30 & 15.61 \\
$\tau, \mathrm{M \kappa c}$ & $14-16$ & $30-32$ & $30-32$ \\
$\Delta P_{\max } / P_{\max }$ & - & $26.65 \%$ & $29.22 \%$
\end{tabular}

Примечание. $J_{s c}$ - плотность тока короткого замыкания, $\xi-$ коэффициент заполнения вольт-амперной характеристики, $P_{\text {max }}-$ максимальная отдаваемая мощность, $\Delta P_{\max } / P_{\max }$ - относительное изменение максимальной мощности по отношению к контрольному образцу.

В силу высокой поверхностной концентрации никеля и наличия поверхностных дефектов, „поверхностные“ кластеры имеют высокую концентрацию и, следовательно, сильнее влияют на время жизни ННЗ. Можно выявить относительный вклад „поверхностных“ и „объемных“ атомов никеля, если удалить поверхностный, сильно легированный никелем слой.

Образцы солнечных элементов изготавливались по вышеприведенной технологии, диффузия никеля проводилась до формирования $p-n$-перехода при $T_{\mathrm{diff}}=800^{\circ} \mathrm{C}$ в течение $t=30$ мин. При этих условиях толщина обогащенного никелем слоя оценивается величиной 2-2.5 мкм [11].

После диффузии никеля с поверхности образцов полировкой удаляли поверхностный слой $\Delta x$ в интервале толщин $0-5$ мкм. После создания $p-n$-перехода и дополнительного термического отжига при $T_{\text {ann }}=750^{\circ} \mathrm{C}$ в течение $t=30$ мин создавались омические контакты. Далее были измерены вольт-амперные характеристики (BAX) СЭ и время жизни $\tau$ (табл. 5). 
Таблица 5. Изменение максимальной мощности и времени жизни ННЗ СЭ в зависимости от толщины удаленного лицевого поверхностного (обогащенного никелем) слоя

\begin{tabular}{c|c|c|c|c|c|c}
\hline$\Delta x$, мКм & 0 & 0.5 & 1 & 1.5 & 2 & 5 \\
\hline$P_{\max }$, мВт/см & 15.40 & 14.97 & 14.37 & 13.64 & 12.74 & 12.00 \\
$\tau$, мкс & $30-32$ & $28-30$ & $26-28$ & $24-26$ & $24-26$ & $24-26$
\end{tabular}

Как видно из таблицы, с увеличением толщины удаленного лицевого поверхностного (обогащенного никелем) слоя параметры СЭ ухудшаются, и после $\Delta x=5$ мкм максимальная мощность падает на $\sim 30 \%$ относительно значений для образцов с $\Delta x=0$ мкм. Результаты измерения времени жизни ННЗ также показали, что с увеличением толщины удаленного лицевого слоя $\tau$ монотонно уменьшается, а после удаления 1.5 мкм почти не изменяется. Поэтому мы можем утверждать, что улучшение параметров солнечного элемента связано с влиянием поверхностного слоя с концентрацией никеля $N_{S} \sim\left(10^{20}-10^{21}\right) \mathrm{cm}^{-3}$ [10] и толщиной в единицы микрометров, образующегося в процессе диффузии.

\section{4. Обсуждение результатов}

Все полученные данные позволяют считать, что легирование никелем увеличивает время жизни НН3 в базе СЭ, увеличивая коэффициент полезного действия. Также установлено, что удаление обогащенного никелем слоя ухудшает параметры солнечного элемента.

Рост времени жизни ННЗ СЭ мы связываем с формированием кластеров атомов никеля в решетке кремния, находящихся в межузельных состояниях, и наличием у них геттерирующих свойств.

В приповерхностных слоях концентрация никеля на 2.5-3 порядка больше, чем в объеме кристалла. Центрами образования кластеров никеля служат атомы кислорода и другие дефекты решетки кремния, в большом количестве находящиеся вблизи поверхности, а также образующиеся в диффузионном слое $n$-типа проводимости. Таким образом, кластеры никеля находятся преимущественно в приповерхностных слоях СЭ, где могут эффективно геттерировать рекомбинационные примеси. Это подтверждается опытами по удалению поверхностного, обогащенного никелем, слоя.

С уменьшением температуры диффузии никеля время жизни ННЗ увеличивается и достигает максимального значения при $T_{\text {diff }}=800-850^{\circ} \mathrm{C}$, более низкие температуры диффузии ухудшают параметры СЭ. Это может быть связано с уменьшением толщины обогащенной никелем области, а также с понижением концентрации атомов никеля при таких температурах диффузии.

\section{5. Заключение}

Таким образом, на основе полученных результатов можно утверждать, что введение атомов никеля является эффективным методом геттерирования рекомбинационных центров в кремнии.

Данный метод в отличие от других существующих методов имеет следующие преимущества:

- метод геттерирования рекомбинационных примесей кластерами никеля является эффективным, технологичным и дешевым методом;

- введение никеля открывает возможность повышения эффективности кремниевого СЭ на 20-25\%;

- при легировании никелем практически не происходит изменений электрических параметров материала, что позволяет его использовать для всех видов электронных приборов на основе кремния.

\section{Финансирование работы}

Работа выполнена в рамках проекта ОТ-Ф2-50 „Разработка научных основ формирования элементарных ячеек $\mathrm{A}^{\mathrm{II}} \mathrm{B}^{\mathrm{VI}}$ и $\mathrm{A}^{\mathrm{III}} \mathrm{B}^{\mathrm{V}}$ в решетке кремния - новый подход в получении перспективных материалов для фотоэнергетики и фотоники“.

\section{Конфликт интересов}

Авторы заявляют, что у них нет конфликта интересов.

\section{Список литературы}

[1] И.Б. Чистохин, К.Б. Фрицлер. Письма ЖТФ, 46 (21), 11 (2020).

[2] P. Papakonstantinou, K. Somasundram, X. Cao, W.A. Nevin. J. Electrochem. Soc., 148 (2), 36 (2001).

[3] Б.И. Фукс. ФТП, 48 (12), 1704 (2014).

[4] И.Е. Панайотти, Е.И. Теруков, И.С. Шахрай. Письма ЖТФ, 46 (17), 3 (2020).

[5] В.А. Харченко. Изв. вузов. Матер. электрон. техн., 21 (1), 5 (2018).

[6] 3.Ю. Готра. Справочник по технологии микроэлектронных устройств (М., Камерян, 1986).

[7] Ю.А. Якимов, Е.А. Климанов. Прикл. физика, № 3, 15 (2015).

[8] Ю.И. Бохан, В.С. Каменков, Н.К. Толочко. ФТП, 49 (2), 278 (2015).

[9] В.А. Перевощиков, В.Д. Скупов. Письма ЖТФ, 25 (8), 50 (1999).

[10] J. Lindroos, D. P. Fenning, D. J. Backlund, E. Verlage, A. Gorgulla, S.K. Estreicher, H. Savin, T. Buonassisi. J. Appl. Phys., 113, 204906 (2013).

[11] F.H.M. Spit, D. Gupta, K.N. Tu. Phys. Rev. B, 39 (2), 1255 (1989).

[12] Ю.Я. Гафнер, С.Л. Гафнер, П. Энтель. ФТТ, 46 (7), 1287 (2004).

[13] B.A. Abdurakhmanov, M.K. Bakhadirkhanov, K.S. Ayupov, H.M. Iliyev, E.B. Saitov, A. Mavlyanov, H.U. Kamalov. J. Nanosci. Nanotechnol., 4 (2), 23 (2014). 
[14] M.K. Bakhadyrkhanov, B.K. Ismaylov, S.A. Tachilin, K.A. Ismailov, N.F. Zikrillaev. SPQEO, 23 (4), 361 (2020).

[15] M.K. Bakhadyrkhanov, K.A. Ismailov, B.K. Ismaylov, Z.M. Saparniyazova. SPQEO, 21 (4), 300 (2018).

[16] А.С. Астащенков, Д.И. Бринкевич, В.В. Петров. Докл. БГУИР, 8 (38), 37 (2018).

[17] М.К. Бахадырханов, С.Б. Исамов, З.Т. Кенжаев, С.В. Ковешников. Письма ЖТФ, 45 (19), 3 (2019).

[18] M.K. Bakhadyrkhanov, S.B. Isamov, Z.T. Kenzhaev, D. Melebaev, Kh.F. Zikrillayev, G.A. Ikhtiyarova. Appl. Solar Energy, 56 (1), 13 (2020).

[19] В.В. Тогатов, П.А. Гнатюк. ФТП, 39 (3), 378 (2005).

[20] K. Bothe, R. Sinton, J. Schmidt. Progr. Photovolt.: Res. Appl., 13, 287 (2005)

[21] B. Aissa, M.M. Kivambe, M.I. Hossain, O.El. Daif, A.A. Abdallah, F. Ali, N. Tabet. Front Nanosci. Nanotechnol., 1 (1), 2 (2012).

[22] Ch. Sun, F.E. Rougieux, D. Macdonald. J. Appl. Phys., 115, 214907 (2014).

[23] H.P. Bonzel. Phys. Status Solidi, 90, 493 (1967).

Редактор Л.В. Шаронова

\section{Effect of nickel on the lifetime of charge carriers in silicon solar cells}

M.K. Bakhadyrkhanov' ${ }^{1}$, Z.T. Kenzhaev' S.V. Koveshnikov ${ }^{1}$, K.S. Ayupov' ${ }^{1}$, E.Zh. Kosbergenov ${ }^{2}$

${ }^{1}$ Tashkent State Technical University, 100095 Tashkent, Uzbekistan

${ }^{2}$ Karakalpak State University, 230112 Nukus, Uzbekistan

Abstract It has been shown experimentally that nickel clusters on the surface of a silicon sample contain a large amount of oxygen and recombination impurities $-\mathrm{Cu}, \mathrm{Fe}, \mathrm{Cr}$, and so shows good gettering properties of clusters. The optimum temperature of nickel diffusion into silicon is determined as $800-850^{\circ} \mathrm{C}$. Doping with impurity nickel atoms with the formation of clusters makes it possible to increase the lifetime of nonequilibrium charge carriers in the base of a solar cell by up to 2 times, while the formation of a nickel-enriched region in the face layer is more efficient. It is shown that the effect of additional doping with nickel weakly depends on the sequence of the processes of nickel diffusion and the creation of a working $p-n$-junction. 